Keywords: anticancer drug; Signal transduction pathways, endocrine/oestrogen-related cancers; tubulin-targeted agents; Akt PKB; apoptosis; mTOR complex (mTORC); multifaceted tumour therapeutic

\title{
Targeted NF1 cancer therapeutics with multiple modes of action: small molecule hormone-like agents resembling the natural anticancer metabolite, 2-methoxyoestradiol
}

\author{
Yu-chi Shen ${ }^{1,2}$, Ravi Upadhyayula1,3,8, Stephanie Cevallos ${ }^{1,4,8}$, Ryan J Messick ${ }^{1}$, Tammy Hsia ${ }^{1,5}$, \\ Mathew $\mathrm{P}$ Leese ${ }^{6}$, Douglas M Jewett ${ }^{1}$, Daysha Ferrer-Torres ${ }^{1,5}$, Therese M Roth ${ }^{1}$, Wolfgang Dohle ${ }^{6}$, \\ Barry V L Potter ${ }^{6,7}$ and Kate F Barald ${ }^{\star}, 1,2,3,4,5$
}

${ }^{1}$ Department of Cell and Developmental Biology, University of Michigan Medical School, Ann Arbor, Michigan 48109-2200, USA; ${ }^{2}$ Department of Biomedical Engineering, College of Engineering, University of Michigan, Ann Arbor, Michigan 48109, USA; ${ }^{3}$ Neuroscience Program, University of Michigan, Ann Arbor, Michigan 48109, USA; ${ }^{4}$ NIH PREP program, Ann Arbor, Michigan 48109, USA; ${ }^{5}$ Cancer Biology Summer Program, University of Michigan, Ann Arbor, Michigan 48109, USA; ${ }^{6}$ Medicinal Chemistry, Department of Pharmacy and Pharmacology, University of Bath, Claverton Down, Bath BA2 7AY, UK and ${ }^{7}$ Department of Pharmacology, University of Oxford, Mansfield Road, Oxford OX1 3QT, UK

Background: Both the number and size of tumours in NF1 patients increase in response to the rise in steroid hormones seen at puberty and during pregnancy. The size of tumours decreases after delivery, suggesting that hormone-targeting therapy might provide a viable new NF1 treatment approach. Our earlier studies demonstrated that human NF1 tumour cell lines either went through apoptosis or ceased growth in the presence of 2-methoxyoestradiol (2ME2), a naturally occurring anticancer metabolite of $17-\beta$ estradiol. Previous reports of treatment with sulfamoylated steroidal and non-steroidal derivatives of 2ME2 showed promising reductions in tumour burden in hormone-responsive cancers other than NF1. Here we present the first studies indicating that 2ME2 derivatives could also provide an avenue for treating NF1, for which few treatment options are available.

Methods: STX3451, (2-(3-Bromo-4,5-dimethoxybenzyl)-7-methoxy-6-sulfamoyloxy-1,2,3,4-tetrahydroisoquinoline), a non-steroidal sulphamate analogue of 2ME2, was tested in dose-dependent studies of malignant and benign NF1 human tumour cell lines and cell lines with variable controlled neurofibromin expression. The mechanisms of action of STX3451 were also analysed.

Results: We found that STX3451-induced apoptosis in human malignant peripheral nerve sheath tumour (MPNST) cell lines, even in the presence of elevated oestrogen and progesterone. It inhibits both PI3 kinase and mTOR signalling pathways. It disrupts actin- and microtubule-based cytoskeletal structures in cell lines derived from human MPNSTs and in cells derived from benign plexiform neurofibromas. STX3451 selectively kills MPNST-derived cells, but also halts growth of other tumour-derived NF1 cell lines.

Conclusion: STX3451 provides a new approach for inducing cell death and lowering tumour burden in NF1 and other hormoneresponsive cancers with limited treatment options.

\footnotetext{
${ }^{*}$ Correspondence: Professor KF Barald; E-mail: kfbarald@umich.edu

${ }^{8}$ These two authors contributed equally to the work.
}

Received 19 February 2015; revised 1 September 2015; accepted 2 September 2015; published online 13 October 2015 
Neurofibromatosis type I (NF1) is an autosomal dominant disorder associated with loss-of-function mutations in the NF1 tumour suppressor gene that encodes the multi-functional protein Neurofibromin (Wallace et al, 1990; Xu et al, 1990; Roth et al, 2008a; Gottfried et al, 2010). One in 2500-3500 individuals is affected by NF1, worldwide. The symptoms can vary from relatively benign small cutaneous tumours to highly aggressive malignant peripheral nerve sheath tumours (MPNST; Jett and Friedman, 2010). Benign Schwann cell-derived tumours of the peripheral nerve sheath called neurofibromas, or plexiform neurofibromas (PNF) are the most commonly found lesions and can be located throughout the nervous system (Korf, 1999). Even benign NF1 tumours can be disfiguring and painful, and it is estimated that about 10 per cent of benign tumours can become MPNST (Upadhyaya, 2011).

Conventional treatments for PNF and MPNST tumours include surgical removal of all or part of the tumour, which is difficult to perform without damage to nerves. Although several targeted drug therapies have been developed (Johansson et al, 2008; Jessen et al, 2013; Ohishi et al, 2013) to date, no therapeutics have significantly reduced NF1 tumour burden in phase III trials (Zehou et al, 2013). Therefore, there is a pressing need to develop additional, novel effective therapeutics that target NF1 tumours without affecting the surrounding non-myelinating or myelinating Schwann cells.

Previous studies indicate that elevated levels of steroid hormones seen at puberty and during pregnancy increase both the size and number of NF1 lesions and that formerly benign tumours can become malignant in an environment in which progesterone (McLaughlin and Jacks, 2003) or oestrogen levels are elevated (Roth et al, 2008a; Li et al, 2010). Our group previously demonstrated a negative correlation between the expression of oestrogen/progesterone receptors and Neurofibromin levels in mouse ES-derived Schwann cells of known NF1 status and in two human NF1 tumour cell lines. We found that the MPNST line, ST88, had significantly increased proliferation rates in the presence of both oestrogen and progesterone (Roth et al, 2008b). Together, these observations suggest that agents that target hormoneresponsive pathways might provide a potential therapeutic approach, especially for NF1-related MPNST.

We previously demonstrated that 2-methoxyoestradiol (2ME2), a naturally occurring metabolite of $17-\beta$ estradiol, significantly inhibited growth and proliferation of both PNF and ST cell lines, and induced apoptosis in ST cells (Roth et al, 2008b). 2ME2 had been shown to cause growth arrest of other hormone-dependent or -independent tumour cells both in vitro (Qadan et al, 2001; Garcia et al, 2006) and in xenografted or transgenic mouse models (Ireson et al, 2004; Ganapathy et al, 2009), and has been the focus of clinical trials in the US for a wide variety of tumours, but not for NF1.

Although 2ME2 appears to have a modest pharmacokinetic profile (Bruce et al, 2012), sulfamoylated variants of 2ME2 including the 'bisMATEs', 2ME2-3,17-O,O-bis-sulphamate (2ME2bisMATE, STX140) its close analogue STX243 (Leese et al, 2006; Newman et al, 2008) as well as STX641 and nonsteroidal sulphamate derivatives (Leese et al, 2010; Dohle et al, 2014; Stengel et al, 2014) exhibited therapeutic properties that were significantly improved relative to $2 \mathrm{ME2}$. 2-methoxyoestrone-3-Osulphamate inhibits taxol-stimulated tubulin polymerization (MacCarthy-Morrogh et al, 2000), and two 3,17-O,O-bissulfamates STX140 and STX243 inhibit tubulin polymerization by targeting the colchicine-binding site on tubulin (Stengel et al, 2010). These sulfamoylated derivatives of $2 \mathrm{ME} 2$ display improved bioavailability (100-1000-fold better) and resistance to catabolism, compared with 2ME2 (Ireson et al, 2004). Moreover, they can be delivered orally and are highly effective against many human cancer cell types assessed in vitro and also against human tumour cell lines engrafted into mice (Ireson et al, 2004; Chander et al, 2007). In combination, 2-MEbisMATE (STX140) and 2-deoxyglucose exhibit synergy in reducing tumour volume and STX140 may sensitise tumours to inhibition of glycolysis (Tagg et al, 2008). Another novel 2ME2 variant, STX3451 (2-(3-Bromo-4,5dimethoxybenzyl)-7-methoxy-6-sulfamoyloxy-1,2,3,4-tetrahydroisoquinoline; Figure 1A), is a non-steroidal tetrahydroisoquinoline sulphamate derivative that displays high anti-proliferative activity across the NCI 60 cell line panel (average GI $_{50} 50 \mathrm{~nm}$; Dohle et al, 2014). The ability of STX3451, like STX140, to disrupt normal microtubule dynamics through binding to the colchicine site in a cell-free system appears to make a significant contribution to this compound's anti-proliferative effects (Dohle et al, 2014).

In this study, we gained insight into the cellular actions of this next generation of $2 \mathrm{ME} 2$ variants and their potential efficacy as therapeutics for NF1, alone or in combination with inhibitors of PI3K and mTOR pathways, which were tested concomitantly. We found that both bisMATEs and several non-steroidal variants have profound inhibitory effects on cell proliferation in the human PNF cell line, and induce apoptosis in the MPNST-derived ST88 and S462 cell lines. STX3451, in particular, affects both the microtubule- and actin-based cytoskeleton as well as caspases-3 levels of ST88 cells. Non-steroidal variants of $2 \mathrm{ME} 2$ thus provide a novel and potentially powerful therapeutic for NF1-related tumours.

MATERIALS AND METHODS

Drug synthesis. STX2484, STX2895 and STX3451 were synthesised as described (Leese et al, 2010; Dohle et al, 2014). The compounds exhibited spectroscopic and analytical data in accordance with their structures (Figure 1A) and were pure, as determined by high-performance liquid chromatography.

Cell culture. ST88 and PNF human NF1 tumour cell lines are described in Roth et al (2008b). S462, a cell line derived from a human NF1 MPNST (Frahm et al, 2004), was provided by Dr Karen Cichowski, Harvard University, and cultured in $10 \%$ FBS/DMEM. U2OS human osteosarcoma cells (Grossel et al, 1999) and HEK293 cells (Shaw et al, 2002), both $\mathrm{NF} 1^{+/+}$, were provided by Dr Diane Fingar, University of Michigan, and grown in DMEM with $10 \%$ FBS.

Cell viability assays. Cells were plated in 96-well plates $\left(1 \times 10^{4}\right.$ per well). The agents (Figure 1) at concentrations of 100, 300, and $600 \mathrm{~nm}$ were dissolved in vehicle (DMSO; Sigma-Aldrich, St Louis, MO, USA) and added to the wells $2 \mathrm{~h}$ after plating the cells. For hormone treatments, $1 \mu \mathrm{M}$ oestrogen and/or $1 \mu \mathrm{M}$ progesterone (Sigma-Aldrich) were added, alone or with $300 \mathrm{nM}$ STX3451 as indicated. Hormones and STX3451 were replenished after 2 days of culture. Cell growth was assessed using CellTiter 96 (Promega, Madison, WI, USA; Roth et al, 2007, 2008b).

Western blots. The following reagents/inhibitors were dissolved in DMSO: STX3451; wortmannin (EMD Chemicals); KU0063794 (Tocris Bioscience, Bristol, UK), which inhibits both mTOR complex (mTORC1) and mTOC2; colchicine (from Sigma-Aldrich). Cells $\left(2 \times 10^{5}\right)$ were plated in serum free (SF) medium for $18-24 \mathrm{~h}$, then treated with the reagents. After $30 \mathrm{~min}$, the SF medium was replaced with complete medium $(\mathrm{CM})$ containing the same reagents for $24 \mathrm{~h}$. Cell lysates were subjected to western blotting as described previously (Bianchi et al, 2005). Blots were incubated with antibodies (all from Cell Signaling Technology, Danvers, MA, USA) to phosphorylated-AKT (pAKT) S473 or T308 (1:2000), phosphorylated S6K1 (pS6K1) T389 (1:2000), total AKT (1:10 000), total pS6K1 (1:10000). Anti-GAPDH (1:4000-1:8000, from EMD Millipore, Billerica, MA, USA) was used to assess equal protein loading. Proteins were visualised with horseradish peroxidase (HRP) conjugated anti-rabbit or anti-mouse secondary antibodies (Jackson Immunoresearch Laboratories, West Grove, PA, USA) and 
A<smiles>COc1cc2c(cc1OC)CN(Cc1cc(OC)c(OC)c(OC)c1)CC2</smiles>

STX2484 Chemical formula: $\mathrm{C}_{20} \mathrm{H}_{26} \mathrm{~N}_{2} \mathrm{O}_{7} \mathrm{~S}$ molecular weight: 438.50

B $2 \eta \mathrm{ST} 88 / 0.1 \mu \mathrm{M}$ 2ME2 analogues

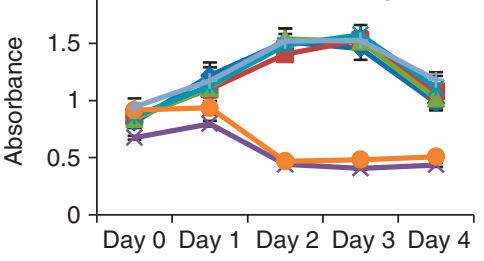

C $\quad 1.5]^{\mathrm{PNF} / 0.1 \mu \mathrm{M} 2 \mathrm{ME} 2 \text { analogues }}$

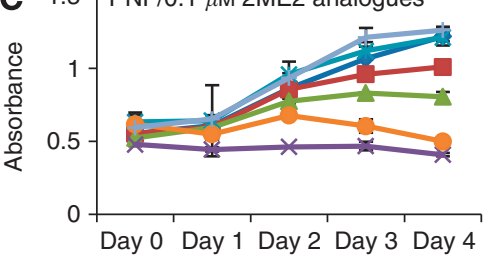

D $2, \mathrm{~S} 462 / 0.3 \mu \mathrm{M} \mathrm{STX3451}$

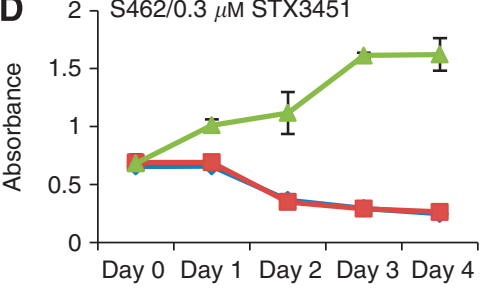

E $\quad 1]$ ST88/hormones
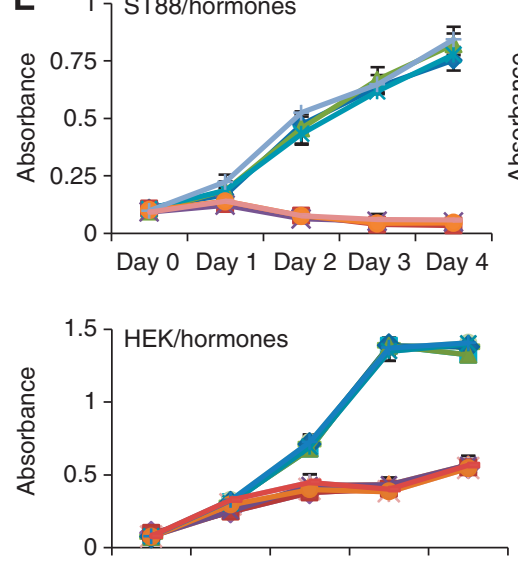

Day 0 Day 1 Day 2 Day 3 Day 4<smiles>CCc1cc2c(cc1OC)CCN(Cc1cc(OC)c(OC)c(OC)c1)C2</smiles>

STX2895 Chemical formula: $\mathrm{C}_{21} \mathrm{H}_{28} \mathrm{~N}_{2} \mathrm{O}_{6} \mathrm{~S}$ molecular weight: 436.52
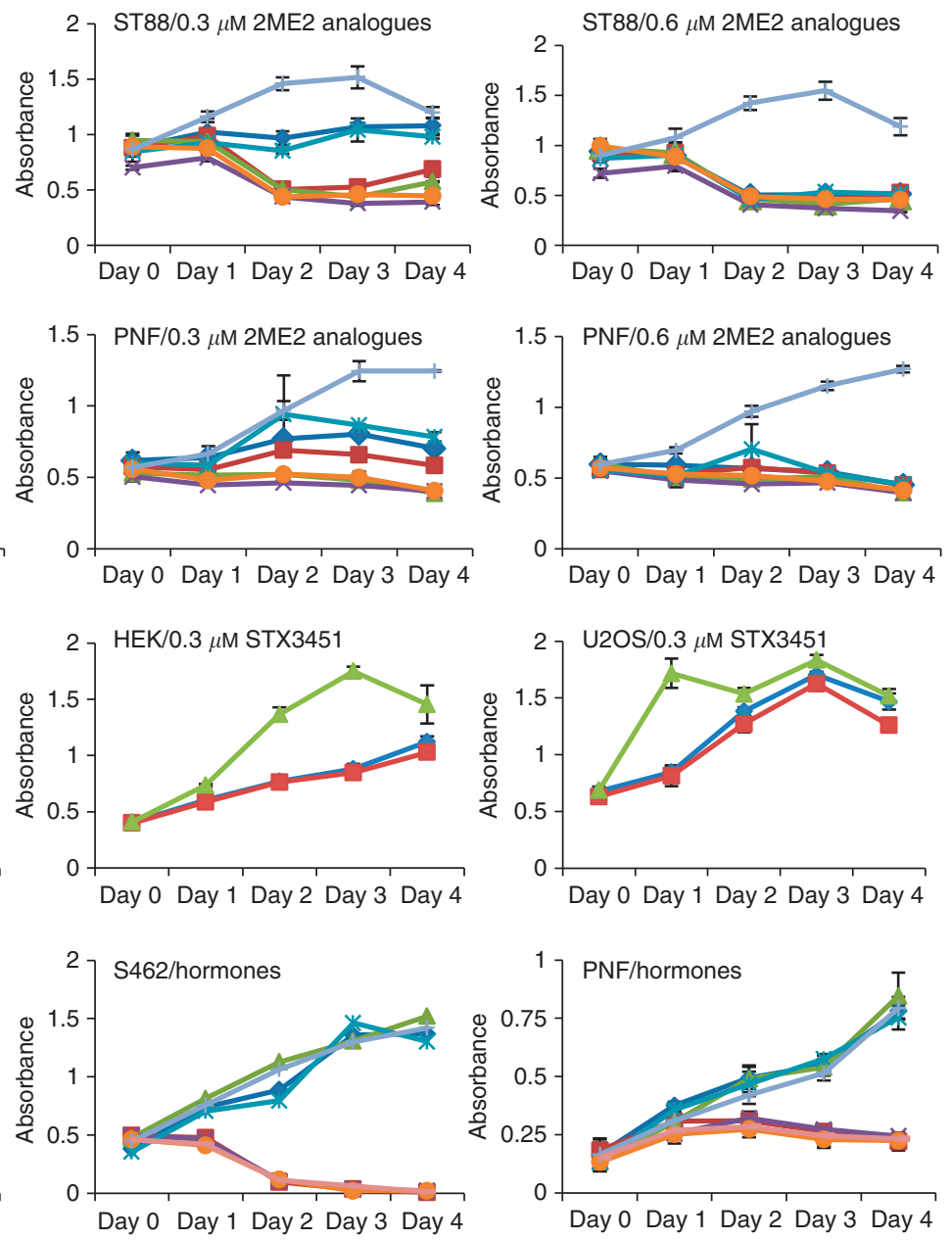

Figure 1. Cell proliferation in response to various specified doses of analogues of $2 \mathrm{ME} 2$ analogues and non-steroidal sulphamate derivatives as well as hormones. (A) Chemical structures of STX2484, STX2895, and STX3451. Three different concentrations $(0.1 \mu \mathrm{M}, 0.3 \mu \mathrm{M}$, and $0.6 \mu \mathrm{M})$ of the compounds were used to test proliferation and viability of human NF1 tumour-derived cell lines. (B) ST88 human MPNST cells; (C) PNF human benign peripheral nerve sheath tumour cells. $\rightarrow$ STX140; - -STX2484; $\rightarrow$ STX243; $\longrightarrow$ STX2895; $\rightarrow$ STX641; $\rightarrow$ STX3451; $\rightarrow$ DMSO vehicle. (D) S462, HEK293, and U2OS cells were treated with $0.1 \mu \mathrm{M} \longrightarrow, 0.3 \mu \mathrm{M} \rightarrow-$ of STX3451, or DMSO vehicle- - (E) Cell proliferation in response to hormones and STX3451. Oestrogen $(1 \mu \mathrm{M})$, progesterone $(1 \mu \mathrm{M})$, or both were used, alone or with STX3451 $(0.3 \mu \mathrm{M}) . \rightarrow-\mathrm{DMSO}$ and ethanol vehicles; $-0.3 \mu \mathrm{M} \mathrm{STX3451;} \mathrm{-}-$ progesterone; - progesterone with STX3451; $\multimap$ oestrogen; - oestrogen with STX3451; -- oestrogen and progesterone; -oestrogen, progesterone, and STX3451.

chemiluminescent HRP substrate (EMD Millipore). Bands were quantified with ImageJ software (NIH, Bethesda, MD, USA). Statistically significant differences were determined using Student's $t$-test. A $P$-value of $P<0.05$ was considered significant.
Immunohistochemistry. $40000-80000$ cells on $0.1 \%$ porcine gel-coated cover slips were treated with DMSO, STX3451, wortmannin, KU0063794, or colchicine for various time periods. Immunocytochemistry and counter-staining with DAPI 
(4',6-diamidino-2-phenylindole) were carried out as reported previously (Roth et al, 2008b). Focal adhesion plaques, actin cytoskeleton, and microtubules were visualised using antibodies for phospho-paxillin (1:100, Cell Signaling Technology), Alexa Fluor 488-phalloidin (1:200, Thermo Fisher Scientific, Waltham, MA, USA), and $\alpha$-tubulin (1:500, Sigma-Aldrich), respectively. Apoptosis was assessed by an anti-phospho-caspase- 3 antibody (1:200, Cell Signaling Technology). Fluorescent (Alexa Fluor 488 or 594) anti-rabbit or anti-mouse secondary antibodies (Thermo Fisher Scientific) were used for visualising the labelled cells. Fluorescence micrographs were taken with an Olympus BX-51 microscope and processed with Adobe Photoshop (San Jose, CA, USA).

3D cell spheroid formation and testing. 96-well plates were coated with $50 \mu \mathrm{l} 1.5 \%$ agarose (Friedrich et al, 2009) allowed to solidify, and plated with 10000 ST88 or PNF cells. After $60 \mathrm{~h}$ of incubation, spheroids had formed. Half of the medium was replaced with fresh reagents in CM and the cells were incubated for 4 additional days. Photographs of the spheroids were taken with a Leitz Diavert inverted microscope (Leica Microsystems GmbH, Wetzlar, Germany) and processed with Adobe Photoshop.

\section{RESULTS}

Analogues of 2ME2BisMATE selectively induce apoptosis in cultured human MPNST cell lines whilst only slowing proliferation in cell lines derived from benign lesions. We tested the ability of six $2 \mathrm{ME} 2$ variants and non-steroidal sulphamate derivatives to inhibit cell proliferation in NF1-deficient cell lines. The cell lines included MPNST cell lines ST88 and S462, benign tumour cell line PNF, human embryonic kidney HEK293 cells, human osteosarcoma cell line U2OS, and mouse Schwann-like cells derived from different numbers of the normal NF1 gene $\left(\mathrm{NF}^{+/+}\right.$, D3; $\mathrm{NF}^{+1-}$, SKO; $\mathrm{NF}^{-1-}$, DKO). STX140, STX243, and STX641 are sulfamoylated analogues of 2ME2 (Day et al, 2009). STX2484, STX2895, and STX3451 are non-steroidal sulphamate analogues (Figure 1A).

Of the six analogues, we found STX3451 and STX2895 to be the most potent, causing cell death or inhibiting proliferation at $0.1 \mu \mathrm{M}$. At $0.1 \mu \mathrm{M}$, STX3451 and STX2895 reduced cell viability in ST88 cells (Figure 1B), and cell death occurred at a 10-fold lower concentration of STX3451 and STX2895 than at the concentration of $2 \mathrm{ME} 2$ reported previously (Roth et al, 2008b). As with 2ME2, these compounds slightly reduced viability of DKO SC-like cells at $0.6 \mu \mathrm{M}$ (Supplementary Figure 1A), while inhibiting proliferation of PNF, SKO SC, and D3 SC-like cells without causing cell death in these cells (Figure 1C, Supplementary Figure 1B and C).

We found that STX3451 promoted cell death in S462 cells and slowed the growth of HEK293 cells, compared with the DMSO control treatment. However, proliferation of U2OS was not affected by STX3451 (Figure 1D), indicating that the cell death effect of STX3451 is selective for the malignant-tumour-derived ST88 and S462 cells.

To characterise STX3451-induced cell death in ST88 cells, we treated cells with $0.3 \mu \mathrm{M}$ STX3451 in all of the experiments described below (similar effects were also observed at $0.1 \mu \mathrm{M}$ ). We observed that by $72 \mathrm{~h}, \sim 55 \%$ of all cells treated with STX3451 detached from the plate. More than $60 \%$ of these detached cells were dead, and the percentage of dead cells did not increase significantly between 48 and $72 \mathrm{~h}$ (data not shown). This result is consistent with our viability results (Figure $1 \mathrm{~B}$ ) and demonstrates that most cell death occurred between 24 and $48 \mathrm{~h}$.

We also examined the effect of STX3451 on hormone-induced cell proliferation. In each of the cell lines ST88, S462, and PNF, proliferation significantly increased after progesterone or oestrogen treatment. However, STX3451 caused apoptosis in ST88 cells even when these hormones were present and demonstrably promoting cell growth. In general, ST88 was the most sensitive cell line, with cell death occurring at $0.6 \mu \mathrm{m}$ for all tested compounds. STX3451 had a similar effect on S462 cells to that observed in ST88 cells (Figure 1E). Addition of STX3451 to the PNF cell culture severely reduced the proliferation of PNF cells, although the viability of the remaining PNF cells was not affected (Figure 1E) and we found no evidence of apoptosis.

Although HEK cells did not respond to either oestrogen or progesterone, STX3451 significantly slowed proliferation in these cells, either alone or in combination with progesterone or oestrogen (Figure 1E). These results suggest that STX3451 might prove an effective potential therapeutic agent for treating NF1 tumour progression that results from elevation of hormone levels during puberty and pregnancy. We therefore focused on the mechanism of action of STX3451 in ST88 and PNF cells in subsequent experiments.

STX3451 disrupts cytoskeletal structures as well as focal adhesion plaques and causes nuclear blebbing, disintegration, and/or fragmentation in ST88 cells. We observed that before detaching from the culture dish, STX3451-treated ST88 cells became rounded, indicating cytoskeleton and adhesion changes in these cells. In our previous study, 2ME2 has been shown to disrupt microtubules (Roth et al, 2008b).We extended the study to observe effects of STX3451 on both microtubules and actin microfilaments.

Under control conditions (DMSO), microtubules in ST88 cells were distributed in perinuclear regions and throughout the cytoplasm. Similar to 2ME2, STX3451 treatment resulted in shape changes and microtubule redistribution. Long, straight microtubules were no longer seen, and the staining was more concentrated in perinuclear regions (Figure 2A), indicating that STX3451 disrupted microtubular structures in these cells.

We also found that STX3451 profoundly affected the actinbased cytoskeleton. Using phalloidin, we observed that instead of the long, straight actin-based stress fibres seen in DMSO-treated cells, ST88 cells that were still attached after 24 and $48 \mathrm{~h}$ in STX3451 had more prominent peripheral lamellipodia with spikes and shorter, disorganised stress fibres (Figure 2A). This suggests that in addition to breaking down microtubules, STX3451 caused reorganisation of actin molecules and disrupted long microfilaments.

To investigate whether apoptosis is one of the mechanisms by which STX3451 decreased viability, we examined the levels of cleaved caspase- 3 in ST88 cells. We found that by $24 \mathrm{~h}$ after treatment with STX3451, the percentage of phospho-caspase3 positive cells was $>3$ times (40\%) of that of cells grown under DMSO control conditions. By $48 \mathrm{~h}, 67 \%$ of the remaining attached cells treated with STX3451 were caspase-3 positive, about six times of that of cells in DMSO control, although the percentage was the same (11\%) between 24 and $48 \mathrm{~h}$ in DMSO (Figure 2B). This result indicates that although these STX3451treated cells had not yet detached from the culture surface, the majority of them were going through the apoptotic pathway. This is consistent with our previous study in which 2ME2 increased apoptosis in ST88 cells by $20 \%$ in $24 \mathrm{~h}$ (Roth et al, $2008 \mathrm{~b}$ ), and it indicates that STX3451 is a more potent inducer of apoptosis than 2ME2.

A characteristic of apoptosis is nuclear condensation and fragmentation (Edinger and Thompson, 2004). We also discovered that after $24 \mathrm{~h}$ of STX3451 treatment, about double the number of abnormal nuclei were seen (Figure 2C), including severely dented, lobed, or fragmented nuclei, compared with cells treated with DMSO alone (Figure 2A). After $48 \mathrm{~h}$, even though there were fewer total cells remaining attached to cover slips under STX3451 treatment conditions, a much higher percentage of the remaining nuclei exhibited abnormal morphologies, 
A

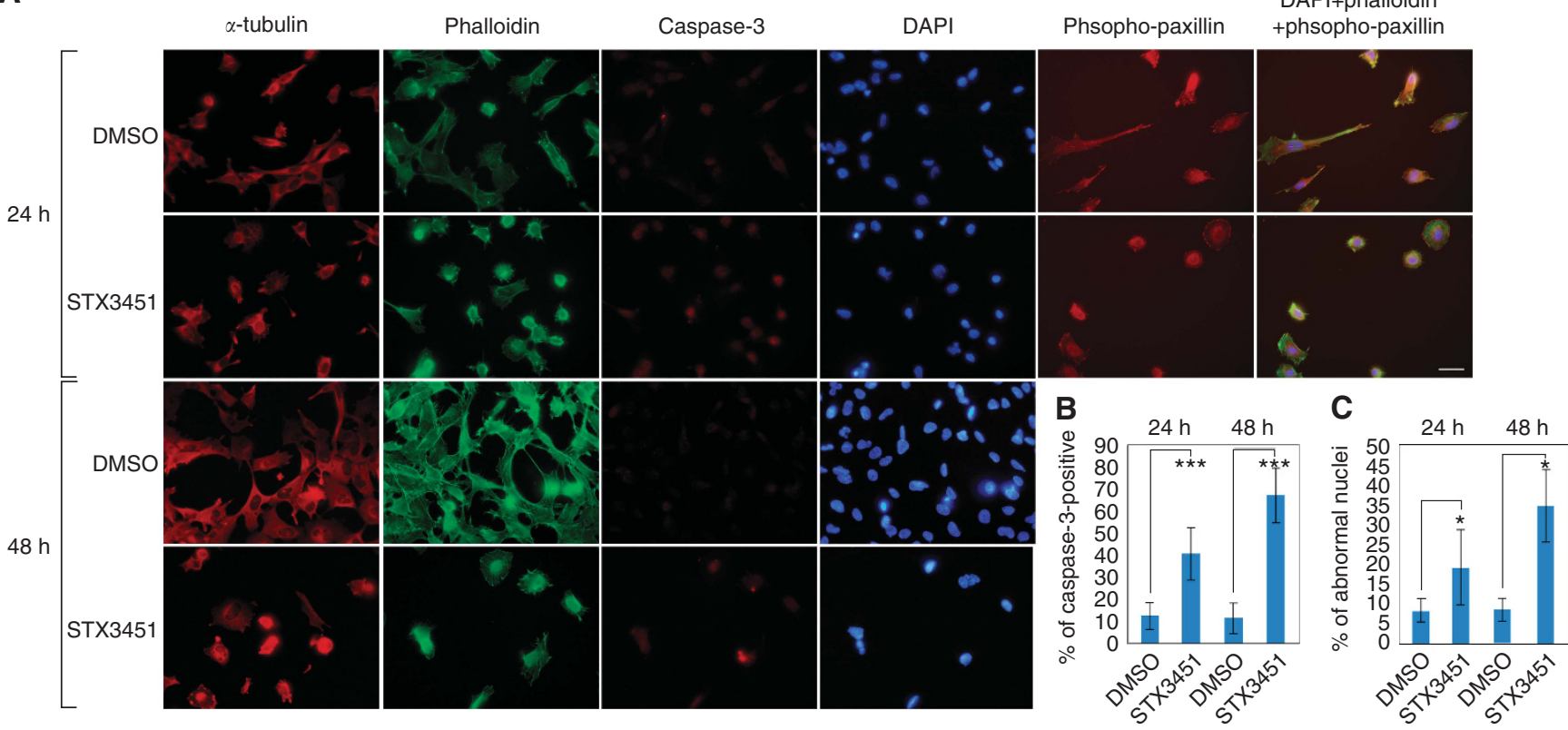

Figure 2. STX3451 treatment caused cytoskeletal structural changes, focal adhesion plaque alterations and apoptotic cell death in ST88 cells. (A) Cells were stained with anti- $\alpha$-tubulin antibody for microtubules, phalloidin for actin filaments, caspase-3 for apoptotic cells, DAPI for nuclei, and phospho-paxillin for focal adhesion sites. Scale bar, $20 \mu \mathrm{m}$. (B) Percentage of caspase-3-positive cells DMSO and STX3451-treated cells. (C) Percentage of abnormal nuclei in both treatments. Statistical significance: ${ }^{\star} P<0.05$; ${ }^{\star \star \star} P<0.005$.

A

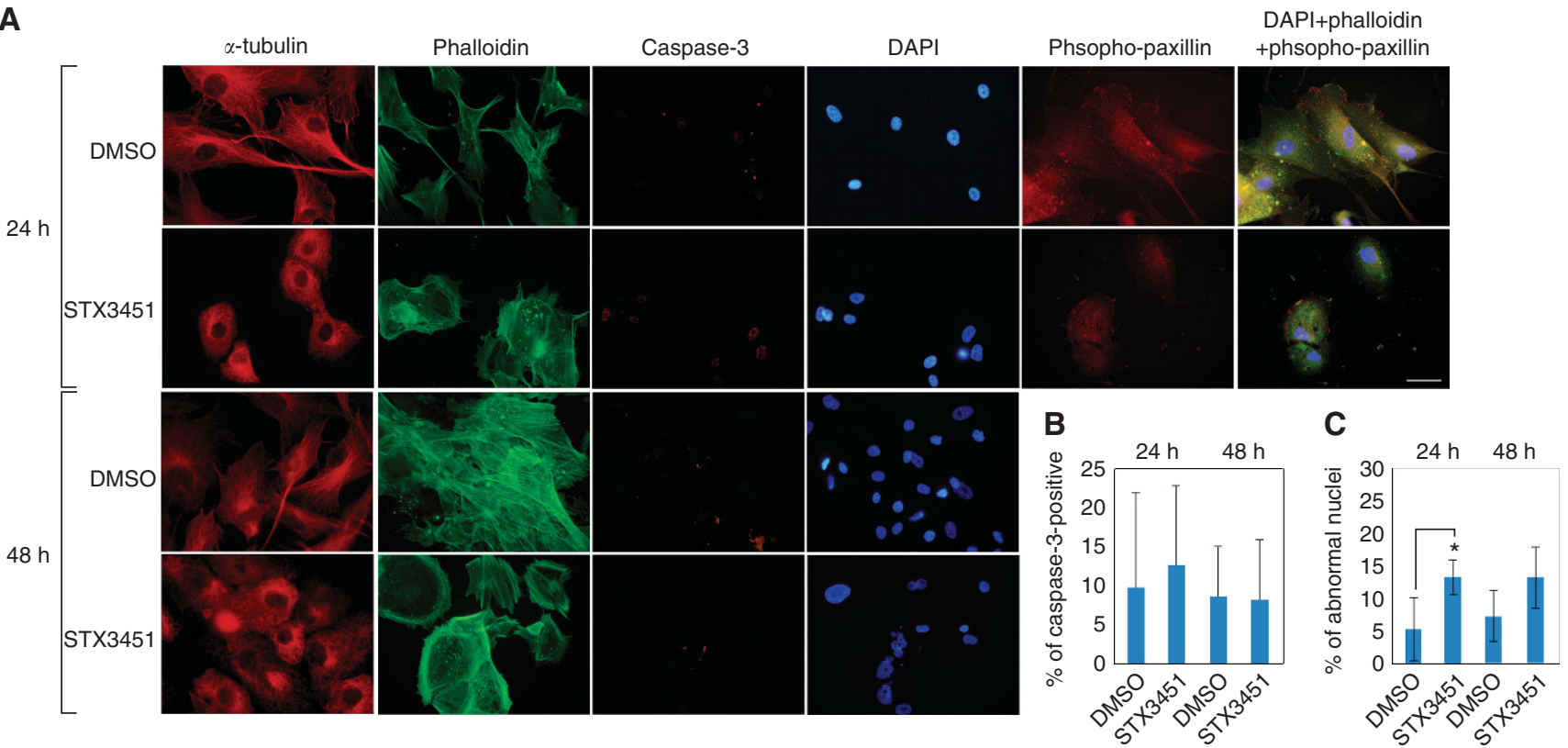

Figure 3. STX3451 treatment caused cytoskeletal structural changes, focal adhesion plaque changes but not apoptotic cell death in PNF cells after $48 \mathrm{~h}$ treatment. (A) $\alpha$-tubulin, phalloidin, caspase-3, DAPI, and phospho-paxillin staining shows both microtubules and microfilaments were affected, especially after $48 \mathrm{~h}$. Scale bar, $50 \mu \mathrm{m}$. (B) Percentage of caspase-3-positive cells DMSO and STX3451-treated cells. (C) Percentage of abnormal nuclei in both treatments. Statistical significance: ${ }^{\star} P<0.05$.

indicating failure of cytokinesis and/or increased cell death (Figure 2C). This is consistent with the results from caspase- 3 staining. The increased incidence of abnormal nuclei (including fragmented nuclei) also supports the conclusion that STX3451 caused ST88 cell death through apoptosis even though cells were still attached to the cell culture surface.
To examine whether STX3451 causes ST88 cell detachment by disrupting focal adhesion plaques, affecting integrin-mediated cytoskeletal reorganisation, we performed immunocytochemistry with a phospho-paxillin antibody (Burridge et al, 1992). Under control conditions, phospho-paxillin tends to be located at the ends of actin filaments, parallel to the long axis of the cell. However, with STX3451 treatment for $24 \mathrm{~h}$, along with disorganised actin 
filaments, phospho-paxillin plaques were randomly oriented (Figure 2A), suggesting disrupted focal adhesion plaques.

The effects of STX3451 on the cytoskeleton in PNF cells resembled STX3451 effects in ST88 cells, but did not cause apoptosis in these cells. Although STX3451 did not reduce viability of PNF cells, we noticed shape changes in these cells. We therefore also examined their cytoskeletal structures. The changes induced in microtubular organisation and distribution by STX3451 were remarkable. With DMSO alone, the microtubules were long, straight, and located throughout the cell with prominent straight bundles around the nucleus. Treatment with STX3451 resulted in patches of microtubules that were short, curled, and randomly oriented. Although no PNF cells detached under any STX3451 treatment conditions after $48 \mathrm{~h}$, the effect of STX3451 on actin filament organisation is marked at $24 \mathrm{~h}$, an effect even more pronounced at $48 \mathrm{~h}$, with strong peripheral fibres and loss of stress fibres, indicating depolymerisation of actin filaments. STX3451 also disrupted adhesion plaques in PNF cells, as shown with phospho-paxillin staining (Figure 3A).

Apoptotic indices (caspase-3 staining results) did not significantly increase under STX3451 treatment (Figure 3A and B), consistent with our earlier viability studies (Roth et al, 2008b). However, we observed an increased number of abnormal nuclei in STX3451-treated PNF cells (Figure 3A and C). These results indicate that the effect of STX3451 on PNF cells is to block cytokinesis and cause cell growth arrest, but not to induce apoptosis in these cells, which is quite a different effect from the effects of STX3451 on malignant-tumour-derived and hormoneresponsive ST88 cells.
STX3451 alters phosphorylation of PI3K downstream targets; synergistic effects are seen with some inhibitors. Loss-offunction of NF1 causes activation of phosphoinositide 3-kinase (PI3K) signalling (Lau et al, 2000). We therefore next sought to determine whether the effect of STX3451 on the tubulin cytoskeleton is direct, or is the result of indirect effects on tubulin through STX3451 effects on PI3K, which has a known tubulin-binding site (Kapeller et al, 1995). We reasoned that the PI3K inhibitor wortmannin could also affect tubulin dynamics through PI3K-tubulin-binding. We also compared the effects of STX3451 on microtubular cytoskeletal elements and the mTOR pathway downstream of Ras, with effects of the mTORC inhibitor KU0063794 (Magnuson et al, 2012) and with STX3451 and KU0063794 in combination.

Our results showed that although STX3451 indeed caused alterations in downstream $\mathrm{PI} 3 \mathrm{~K}$ phosphorylated components, reducing levels of both pAKT S473 and T308 (Figure 4A-C), the effect of STX3451 was not as pronounced as either wortmannin or KU0063794 (Figure 4A-C). However, a combination of STX3451 with wortmannin or with KU0063794 appears to augment inhibition of S473 phosphorylation, although the results were not statistically significant, indicating a possible synergistic effect of both these inhibitors and STX3451 (Figure 4B). Phosphorylation of AKT T308 was not further reduced by the combination of wortmannin or KU0063794 with STX3451 (Figure 4C). These results do not rule out the possibility that the effects of STX3451 on the cytoskeleton are through PI3K or mTOR pathways, but do indicate that other pathways are involved in the cytoskeletal changes caused by STX3451.

We also separated attached from floating cells in cultures treated with STX3451, and evaluated phosphorylation of AKT and of
A

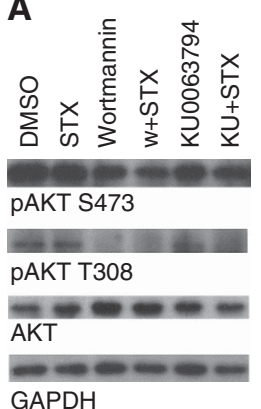

D

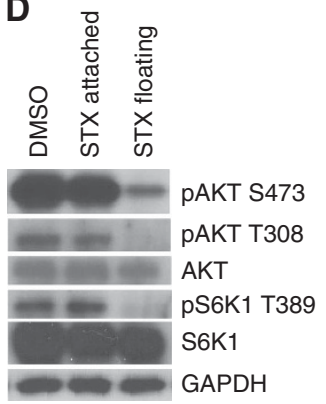

B

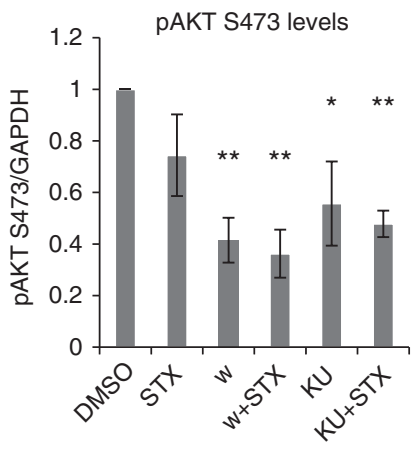

E

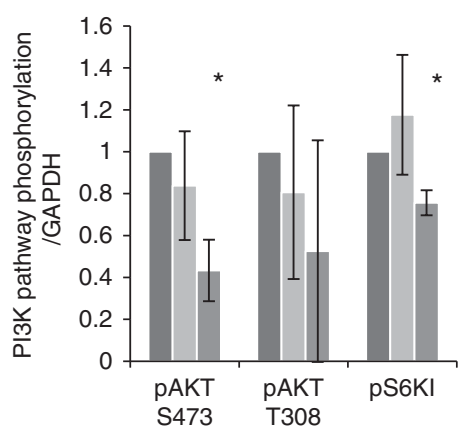

C

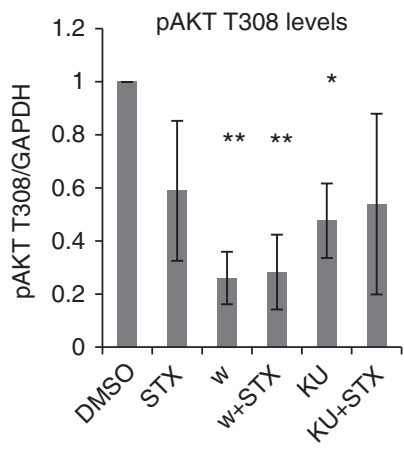

$\mathbf{F}$

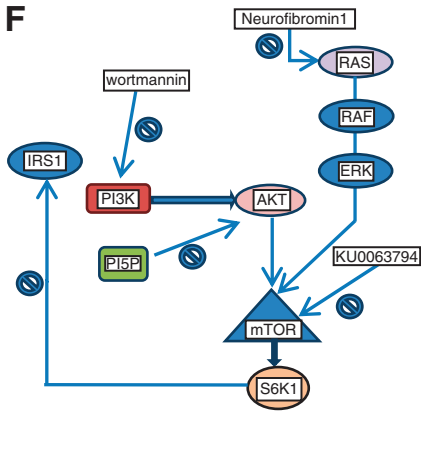

Figure 4. STX3451 reduced levels of pAKT Ser473 and Thr308, but had less effect than PI3K (wortmannin) or mTOR (KU0063794) inhibitors. Both wortmannin and KU0063794 were used at $1 \mu \mathrm{M}$. (A) Western blot of proteins extracted from ST88 cells treated with different conditions. (B and C) Graphical representation $(n=3)$ with statistical significance ${ }^{*} P<0.05$ and $* * P<0.01$. (D) Levels of activated AKT messenger in MPNST tumour cell line in vitro treated with vehicle or STX3451. Both attached and floating cells were collected after $24 \mathrm{~h}$ treatment and cell lysates obtained. (E) Results were then quantified: D DMSO attached cells, STX attached cells, $\quad$ STX floating cells. $n=4$, with statistical significance ${ }^{*} P<0.05$. STX: STX3451; w- wortmannin; KU: KU0063794; (F) Schematic indicating where inhibitors act in the PI3K-AKT pathway. 


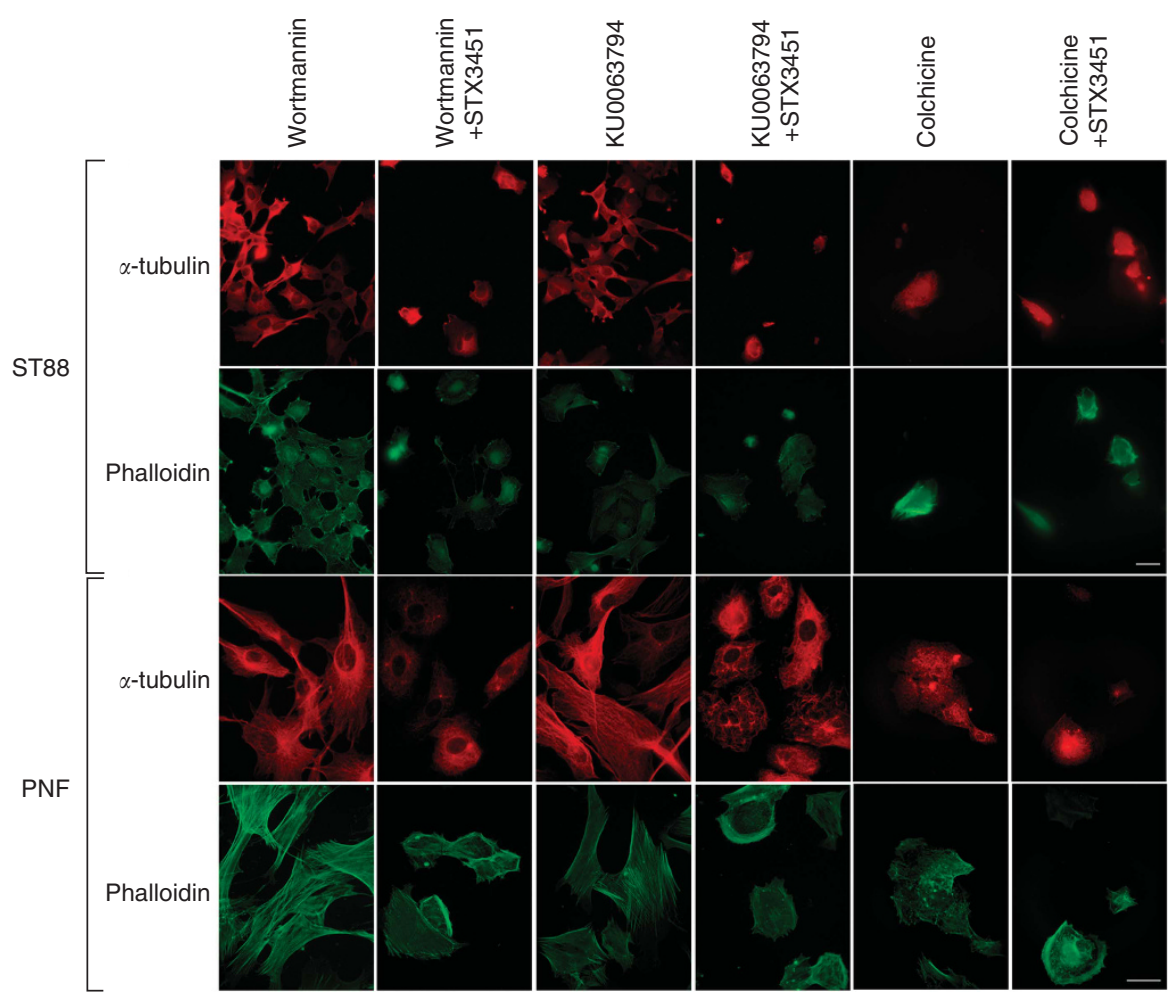

Figure 5. Cytoskeletal structural changes in ST88 and PNF cells after $48 \mathrm{~h}$ treatment with wortmannin, KU0063794, and colchicine, alone or with STX3451. Wortmannin and KU0063794 were at $1 \mu \mathrm{m}$, colchicine at $2.5 \mu \mathrm{m}$. Scale bar, $20 \mu \mathrm{m}$ for ST88; $50 \mu \mathrm{m}$ for PNF.

S6K1, one of the key components in the mTOR pathway. We found that both attached and floating STX3451-treated cells had lower levels of pAKT S473 and T308, but the floating cells had significantly lower levels of S473 and T308 than those of the attached cells (Figure 4D and E). Phosphorylation of S6K1 was found to be slightly increased in attached cells, but was significantly reduced in floating cells (Figure $4 \mathrm{E}$ ), indicating that levels of pS6K1 correlate with the ability of cells to attach to the substratum.

We also examined whether wortmannin or KU0063794 have the same effects as STX3451 on cytoskeleton. We observed that although wortmannin alone did not cause any of the cells to detach or round up, cells were more spread on the substratum than the control cells, indicating structural changes in the microfilament arrays. We found both wortmannin and KU0063794 promoted formation of prominent stress fibres in both ST88 and PNF cells after $48 \mathrm{~h}$ of treatment. However, if STX3451 was included in the treatment conditions, either with wortmannin or KU0063794, cells had shortened stress fibres (Figure 5). This result suggests that STX3451 and the PI3K/mTOR inhibitors have different or opposite effects on actin filament organisation, with the inhibitors causing more polymerisation of actin filaments, whilst treatment with STX3451 results in depolymerisation of these filaments.

Similar microtubular arrays were found in ST88 and PNF cells treated with wortmannin and KU0063794 (Figure 5) to cells cultured in DMSO condition for $48 \mathrm{~h}$ (Figures $2 \mathrm{~A}$ and $3 \mathrm{~A}$ ). However, cells treated with both STX3451 and wortmannin or KU0063794 caused depolymerisation of microtubules, and the cells had an intermediate appearance between exposure to STX3451 alone and inhibitors alone (Figure 5), again suggesting the inhibitors have different effects on microtubules from STX3451 in these cells.

STX3451 and colchicine have different morphological effects on the cytoskeleton of $\mathrm{NF}^{-1-}$ tumour cells. In a cell-free system, STX3451 has been shown to inhibit tubulin assembly and block colchicine binding to tubulin (Dohle et al, 2014). Colchicine binds to $\beta$-tubulin and interferes with polymerisation of tubulin molecules to form microtubules (Luduena and Roach, 1991). We thus examined whether the effects of STX3451 on cytoskeleton were similar to those of colchicine.

We found that colchicine, although depolymerising microtubules (Figure 5), did not result in morphological changes in ST88 cells. Microtubules were disrupted in cells treated with colchicine and STX3451 (Figure 5), as they were in cells treated with either STX3451 alone (Figure 2A) or colchicine alone (Figure 5), indicating that STX3451 and colchicine have similar effects on microtubules in ST88 cells.

Colchicine treatment of PNF cells resulted in completely depolymerised microtubules (Figure 5); cells were even more severely affected than those treated with STX3451 alone (Figure 3A). These results indicate that colchicine has a higher affinity for tubulin molecules and more severely depolymerises microtubules than STX3451. However, colchicine-treated PNF cells (Figure 5), unlike those treated with STX3451 (Figure 3A), were less affected morphologically. Cells treated simultaneously with colchicine and STX3451 had very little if any microtubular structure (Figure 5), which was similar to the effect of treatment with colchicine alone. Combined treatment of cells with colchicine and STX3451 again resulted in rounded cells with thick cortical actin filaments (Figure 5).

Our results demonstrate that STX3451 and colchicine have different effects on cytoskeletal structures: although STX3451 does not completely depolymerise microtubules as colchicine does, colchicine at the concentration we used does not drastically affect actin microfilaments as does STX3451.

Effect of STX3451 on ST88 and PNF 3D spheroids. Previous studies have shown that some drugs that were effective in inducing death in cancer cells in $2 \mathrm{D}$ cultures lost their efficacy in a $3 \mathrm{D}$ environment (Friedrich et al, 2009). We therefore examined the effect of STX3451 in 3D cultures. Our results showed that 4 days 

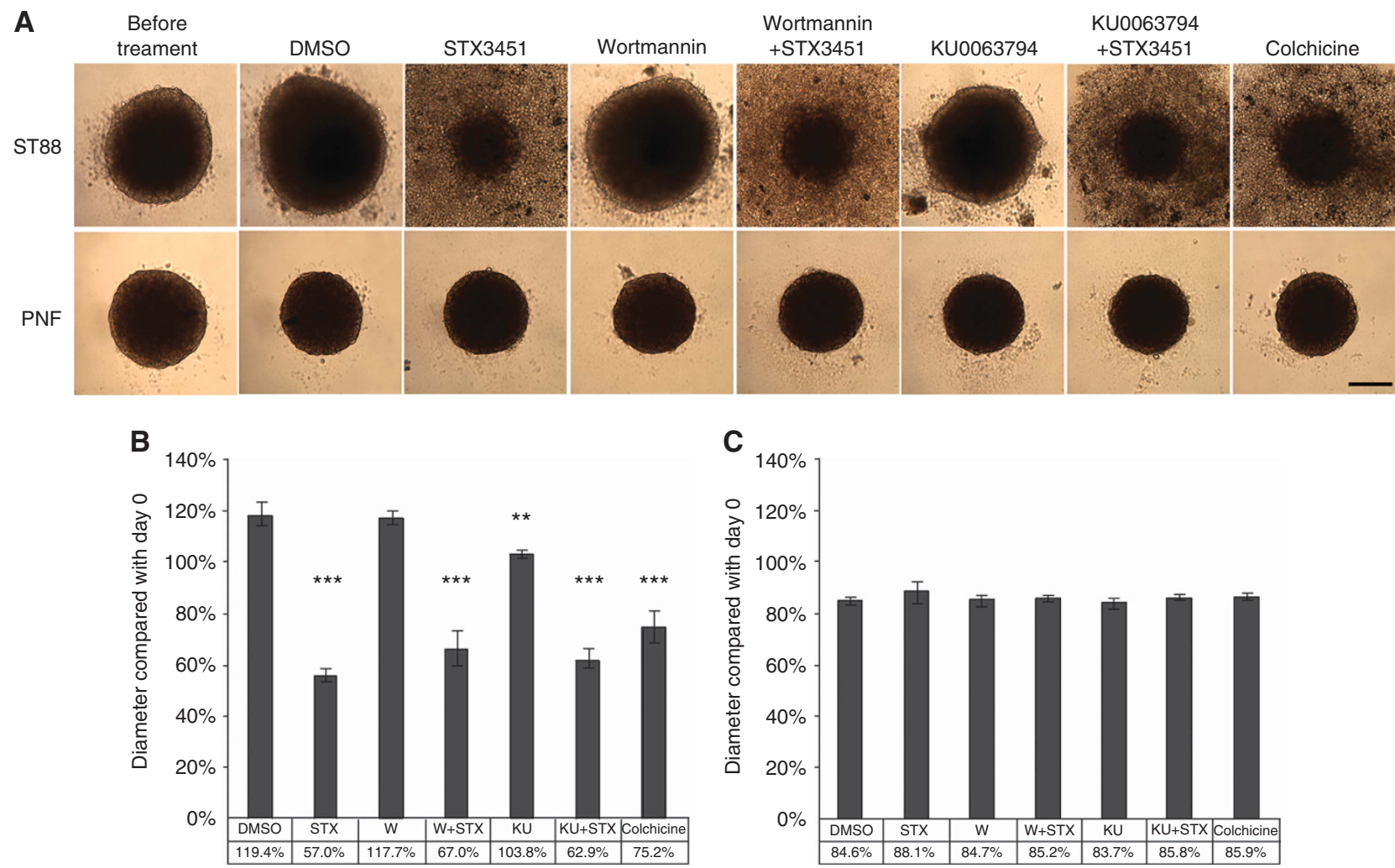

Figure 6. Treatment of STX3451 caused shrinkage of and cell emigration from ST88 but not PNF spheroids. STX3451 was at $150 \mathrm{~nm}$, Wortmannin and KU0063794 were at $0.5 \mu \mathrm{m}$. Treatments were $96 \mathrm{~h}$. Scale bar, $200 \mu \mathrm{m}$. (B) Percentage of average diameters compared with that before treatment of ST88 cells. ${ }^{\star \star} P<0.01$; ${ }^{\star \star \star} P<0.001$. (C) Percentage of average diameters compared with that before treatment of PNF cells.

after treatment with DMSO vehicle, ST88 spheroids grew 20\% in diameter (Figure 6A and B), whereas spheroids treated with STX3451 decreased in diameter to $57 \%$ of their original size. Wortmannin had little effect on the growth of the spheroids, but combinations of wortmannin and STX3451 significantly reduced the size of the spheroids. KU0063794 resulted in smaller spheroids than those in DMSO, growing $\sim 4 \%$ in diameter in 4 days. Combinations of KU0063794 and STX3451 again resulted in much smaller spheroids. Colchicine also significantly reduced the size of ST88 spheroids, but not to the same extent as STX3451 (Figure 6A and B). These results indicate that STX3451 is still effective in promoting ST88 cell death in a 3D culture. Surprisingly, PNF cells formed more compact spheroids than ST88 cells, and over time they became even more compacted (Figure 6A and C). None of the reagents we tested caused shrinkage or dissociation of these spheroids (Figure 6A and C), although cell numbers were not quantified.

\section{DISCUSSION}

With the discovery that human NF1 tumours are responsive to hormones and have elevated hormone receptor levels (McLaughlin and Jacks, 2003; Roth et al, 2008b), hormone analogues capable of interfering with downstream pathways and tumour growth have become an intriguing treatment option to consider. 2ME2 has been used in human clinical trials for a number of hormone-responsive cancers, but its limited bioavailability, short half-life as an active agent, and the ease with which it is catabolized in the intestine and liver make it a less-than-optimal cancer chemotherapeutic. However, sulfamoylation of 2ME2 (Purohit et al, 1998; Leese et al, 2006) leads to enhanced potency, bioavailability, and resistance to catabolism (Ireson et al, 2004; Foster et al, 2008).
Sulfamoylated steroids have the potential to significantly reduce tumour burden in hormone-responsive cancers of all types, including NF1.

We previously showed that $2 \mathrm{ME} 2$ arrests cell growth in PNF cells as well as mouse Schwann cell (SC)-like cells differentiated from $\mathrm{NF}^{-/-}$ES cells (Roth et al, 2008b). In this study, we found that one of the most potent of the sulfamoylated non-steroidal compounds, STX3451, effectively induces cell death in the ST88 and S462 cell lines in vitro at very low concentration $(0.3 \mu \mathrm{M})$. Intriguingly, our results showed that STX3451's apoptotic effect was highly specific for malignant ST88 and S462 cells, and that, although growth of PNF was arrested and that of the human embryonic kidney cell line HEK293 slowed, the drug had no effect on the growth parameters of a human osteosarcoma cell line, U2OS.

We found that apoptosis was induced in ST88 cells and growth arrested in PNF cells by at least two mechanisms, which may be independent. First, STX3451 affects phosphorylation of elements in PI3K and mTOR pathways, both of which are downstream of Neurofibromin's activities as a growth/tumour suppressor. STX3451 significantly inhibits phosphorylation of AKT Ser473, Thr308, and S6KI T389, a major target of mTOR inhibitors (Figure 4F). The effect seen in ST88 cells that detach from the substratum is even more marked than in cells that remain attached to the culture plate and these effects are generally greater than - or at least as effective as - those induced by wortmannin or KU0063794, except that wortmannin is more efficient in reducing phosphorylation at pAKT Thr308.

We found that by $48 \mathrm{~h}$ after treatment with STX3451, the percentage of phospho-caspase-3-positive cells among the remaining attached cells was six times that of that control cells. This result indicates that although these STX3451-treated cells had not yet detached from the culture surface, the majority of them were going through the apoptotic pathway. We also documented that STX3451 
had pronounced effects on both actin and tubulin-based cytoskeletal elements. Disrupting the tubulin cytoskeleton has effects on centriole formation, chromosome separation, cytokinesis, and cellular locomotion (Etienne-Manneville, 2013). Changing the actin cytoskeleton affects cellular morphology, cytokinesis, and locomotion (Pollard and Cooper, 2009). If a tumour cell's ability to move through, for example, connective tissue, is impaired, then ability to metastasise is severely curtailed (Mierke, 2013).

Treatment with STX3451 alone caused ST88 cells to round up, concomitant with the disappearance of long actin-based stress fibres. STX3451 not only disrupted actin filaments, but also affected the morphology of the nucleus: a much higher percentage of cells with aberrant multi-lobed and fragmented nuclei was seen with STX3451. This suggests that STX3451 has two different effects: it inhibits cytokinesis, presumably through its cytoskeletal effects and it promotes apoptosis, presumably through its effects on PI3K/mTOR pathways. Whether these effects are mediated through mitochondria remains to be examined.

2ME2 has been shown to depolymerise microtubules in prostate cancer cells (Mabjeesh et al, 2003), affect microtubules in ST88 and PNF tumour cells (Roth et al, 2008b). STX3451 destabilised the taxol-induced polymerisation of tubulin and successfully competed with colchicine binding to in a cell-free system $\beta$-tubulin (Dohle et al, 2014). Our results showed that STX3451 had a similar effect to that of both STX140 and STX243, which disrupted microtubular structures in ST88 and PNF cells, in agreement with the tubulin polymerisation interference results (Dohle et al, 2014). However, $\mathrm{PI} 3 \mathrm{~K} / \mathrm{mTOR}$ inhibitors did not cause dramatic changes in microtubules. STX3451 in combination with PI3K/mTOR inhibitors resulted in a phenotype similar to STX3451 alone, suggesting that STX3451 is more effective in disrupting microtubules than those inhibitors in ST88 and PNF cells.

It is intriguing that, although STX3451 does not completely disrupt microtubules as colchicine does, colchicine at the concentration we used did not drastically affect actin microfilaments as did STX3451. Therefore, STX3451 affects ST88 and PNF cytoskeletal structures differently from colchicine.

Because our study demonstrated that STX3451 induces apoptosis specifically in the MPNST cell lines ST88 and S462, and arrested the growth of benign PNF cells, even in the presence of elevated oestrogen and progesterone, this drug is a good candidate for proposed preclinical trials involving human NF1 tumour cells engrafted into an immunocompromised NF1 mouse model (Li et al, 2010). Such a model system could also be used to test whether, under conditions in which hormone levels are elevated, the drugs could still induce apoptosis or growth arrest in the tumours. Tests of STX3451 alone or a combination of treatments could be conducted in mouse models that have different levels of neurofibromin, as are found in NF1 patients. Such treatments could provide a much needed treatment for NF1 patients in the future.

\section{ACKNOWLEDGEMENTS}

We would like to thank Drs Christin Carter-Su, Department of Molecular and Integrative Physiology and CMB Programme, University of Michigan for extensive discussions and for critical comments on the manuscript. We would like to thank Dr Karen Cichowski, Harvard University, and Drs Diane Fingar, Kristen J Verhey and Ajit Joglekar, Department of Cell and Developmental Biology and CMB Program (Diane Fingar and Kristen J Verhey) and Biomedical Engineering (Ajit Joglekar) University of Michigan for reagents and many helpful discussions, and Ethan M. Jewett, Department of Statistics, University of California, Berkeley for additional editing of the manuscript.

We thank the Wellcome Trust for VIP funding and BVLP is a Wellcome Trust Senior Investigator (grant 101010).

\section{CONFLICT OF INTEREST}

The authors declare no scientific or financial conflict of interest.

\section{DISCLAIMER}

Barald Laboratory: The studies in this report were not supported by either USA or UK public or private granting sources. Potter Laboratories: the development of STX3451 and similar agents was supported in part by Sterix Ltd., a member of the IPSEN Group.

\section{REFERENCES}

Bianchi LM, Daruwalla Z, Roth TM, Attia NP, Lukacs NW, Richards AL, White IO, Allen SJ, Barald KF (2005) Immortalized mouse inner ear cell lines demonstrate a role for chemokines in promoting the growth of developing statoacoustic ganglion neurons. J Assoc Res Otolaryngol 6: 355-367.

Bruce JY, Eickhoff J, Pili R, Logan T, Carducci M, Arnott J, Treston A, Wilding G, Liu G (2012) A phase II study of 2-methoxyestradiol nanocrystal colloidal dispersion alone and in combination with sunitinib malate in patients with metastatic renal cell carcinoma progressing on sunitinib malate. Invest New Drugs 30: 794-802.

Burridge K, Turner CE, Romer LH (1992) Tyrosine phosphorylation of paxillin and pp125FAK accompanies cell adhesion to extracellular matrix: a role in cytoskeletal assembly. J Cell Biol 119: 893-903.

Chander SK, Foster PA, Leese MP, Newman SP, Potter BVL, Purohit A, Reed MJ (2007) In vivo inhibition of angiogenesis by sulphamoylated derivatives of 2-methoxyoestradiol. Br J Cancer 96: 1368-1376.

Day JM, Foster PA, Tutill HJ, Newman SP, Ho YT, Leese MP, Potter BVL, Reed MJ, Purohit A (2009) BCRP expression does not result in resistance to STX140 in vivo, despite the increased expression of BCRP in A2780 cells in vitro after long-term STX140 exposure. $\mathrm{Br}$ J Cancer 100: $476-486$.

Dohle W, Leese MP, Jourdan FL, Chapman CJ, Hamel E, Ferrandis E, Potter BVL (2014) Optimisation of tetrahydroisoquinoline-based chimeric microtubule disruptors. ChemMedChem 9: 1783-1793.

Edinger AL, Thompson CB (2004) Death by design: apoptosis, necrosis and autophagy. Curr Opin Cell Biol 16: 663-669.

Etienne-Manneville S (2013) Microtubules in cell migration. Annu Rev Cell Dev Biol 29: 471-499.

Foster PA, Ho YT, Newman SP, Kasprzyk PG, Leese MP, Potter BVL, Reed MJ, Purohit A (2008) 2-MeOE2bisMATE and 2-EtE2bisMATE induce cell cycle arrest and apoptosis in breast cancer xenografts as shown by a novel ex vivo technique. Breast Cancer Res Treat 111: 251-260.

Frahm S, Mautner VF, Brems H, Legius E, Debiec-Rychter M, Friedrich RE, Knöfel WT, Peiper M, Kluwe L (2004) Genetic and phenotypic characterization of tumor cells derived from malignant peripheral nerve sheath tumors of neurofibromatosis type 1 patients. Neurobiol Dis 16: 85-91.

Friedrich J, Seidel C, Ebner R, Kunz-Schughart LA (2009) Spheroid-based drug screen: considerations and practical approach. Nat Protoc 4: 309-324.

Ganapathy M, Ghosh R, Jianping X, Zhang X, Bedolla R, Schoolfield J, Yeh IT, Troyer DA, Olumi AF, Kumar AP (2009) Involvement of FLIP in 2-methoxyestradiol-induced tumor regression in transgenic adenocarcinoma of mouseprostate model. Clin Cancer Res 15: 1601-1611.

Garcia GE, Wisniewski HG, Lucia MS, Arevalo N, Slaga TJ, Kraft SL, Strange R, Kumar AP (2006) 2-Methoxyestradiol inhibits prostate tumor development in transgenic adenocarcinoma of mouse prostate: role of tumor necrosis factor-alpha-stimulated gene 6. Clin Cancer Res 12: 980-988.

Gottfried ON, Viskochil DH, Couldwell WT (2010) Neurofibromatosis type 1 and tumorigenesis: molecular mechanisms and therapeutic implications. Neurosurg Focus 28: E8.

Grossel MJ, Baker GL, Hinds PW (1999) cdk6 can shorten G(1) phase dependent upon the N-terminal INK4 interaction domain. J Biol Chem 274: 29960-29967.

Ireson CR, Chander SK, Purohit A, Parish DC, Woo LW, Potter BVL, Reed MJ (2004) Pharmacokinetics and efficacy of 2-methoxyoestradiol and 2-methoxyoestradiol-bis-sulphamate in vivo in rodents. $\mathrm{Br}$ J Cancer 90: 932-937. 
Jessen WJ, Miller SJ, Jousma E, Wu J, Rizvi TA, Brundage ME, Eaves D, Widemann B, Kim MO, Dombi E, Sabo J, Hardiman Dudley A, Niwa-Kawakita M, Page GP, Giovannini M, Aronow BJ, Cripe TP, Ratner $\mathrm{N}$ (2013) MEK inhibition exhibits efficacy in human and mouse neurofibromatosis tumors. J Clin Invest 123: 340-347.

Jett K, Friedman JM (2010) Clinical and genetic aspects of neurofibromatosis 1. Genet Med 12: 1-11.

Johansson G, Mahller YY, Collins MH, Kim MO, Nobukuni T, Perentesis J, Cripe TP, Lane HA, Kozma SC, Thomas G, Ratner N (2008) Effective in vivo targeting of the mammalian target of rapamycin pathway in malignant peripheral nerve sheath tumors. Mol Cancer Ther 7: 1237-1245.

Kapeller R, Toker A, Cantley LC, Carpenter CL (1995) Phosphoinositide 3-kinase binds constitutively to alpha/beta-tubulin and binds to gammatubulin in response to insulin. J Biol Chem 270: 25985-25991.

Korf BR (1999) Neurofibromas and Malignant Tumors of the Peripheral Nerve Sheath. In: Friedman JM (eds). Neurofibromatosis, 3rd edition. The Johns Hopkins University Press: Baltimore, MD, USA, pp 142-161.

Lau N, Feldkamp MM, Roncari L, Loehr AH, Shannon P, Gutmann DH, Guha A (2000) Loss of neurofibromin is associated with activation of RAS/ MAPK and PI3-K/AKT signaling in a neurofibromatosis 1 astrocytoma. J Neuropathol Exp Neurol 59: 759-767.

Leese MP, Jourdan F, Kimberley MR, Cozier GE, Thiyagarajan N, Stengel C, Regis-Lydi S, Foster PA, Newman SP, Acharya KR, Ferrandis E, Purohit A, Reed MJ, Potter BVL (2010) Chimeric microtubule disruptors. Chem Comm 46: 2907-2909.

Leese MP, LeBlond B, Smith A, Newman SP, Di Fiore A, De Simone G, Supuran CT, Purohit A, Reed MJ, Potter BVL (2006) 2-Substituted estradiol bis-sulfamates, multi-targeted anti-tumor agents: Synthesis, in vitro SAR, protein crystallography and in vivo activity. J Med Chem 49: 7683-7696.

Li H, Zhang X, Fishbein L, Kweh F, Campbell-Thompson M, Perrin GQ, Muir D, Wallace M (2010) Analysis of steroid hormone effects on xenografted human NF1 tumor Schwann cells. Cancer Biol Ther 10: 758-764.

Luduena RF, Roach MC (1991) Tubulin sulfhydryl groups as probes and targets for antimitotic and antimicrotubule agents. Pharmacol Ther 49: $133-152$.

Mabjeesh NJ, Escuin D, LaVallee TM, Pribluda VS, Swartz GM, Johnson MS, Willard MT, Zhong H, Simons JW, Giannakakou P (2003) 2ME2 inhibits tumor growth and angiogenesis by disrupting microtubules and dysregulating HIF. Cancer Cell 3: 363-375.

MacCarthy-Morrogh L, Townsend PA, Purohit A, Hejaz HAM, Potter BVL, Reed MJ, Packham G (2000) Differential effects of estrone and estrone-3-O-sulfamate derivatives on mitotic arrest, apoptosis, and microtubule assembly in human breast cancer cells. Cancer Res 60: 5441-5450.

Magnuson B, Ekim B, Fingar DC (2012) Regulation and function of ribosomal protein S6 kinase (S6K) within mTOR signalling networks. Biochem J 441 $1-21$.

McLaughlin ME, Jacks T (2003) Progesterone receptor expression in neurofibromas. Cancer Res 63: 752-755.

Mierke CT (2013) Physical break-down of the classical view on cancer cell invasion and metastasis. Eur J Cell Biol 92: 89-104.

Newman SP, Foster PA, Stengel C, Day JM, Ho YT, Judde JG, Lassalle M, Prevost G, Leese MP, Potter BVL, Reed MJ, Purohit A (2008) STX140 is efficacious in vitro and in vivo in taxane-resistant breast carcinoma cells. Clin Cancer Res 14: 597-606.

Ohishi J, Aoki M, Nabeshima K, Suzumiya J, Takeuchi T, Ogose A, Hakozaki M, Yamashita Y, Iwasaki H (2013) Imatinib mesylate inhibits cell growth of malignant peripheral nerve sheath tumors in vitro and in vivo through suppression of PDGFR- $\beta$. BMC Cancer 13: 224.

Pollard TD, Cooper JA (2009) Actin, a central player in cell shape and movement. Science 326: 1208-1212.

Purohit A, Vernon KA, Hummelinck AE, Woo LW, Hejaz HA, Potter BVL, Reed MJ (1998) The development of A-ring modified analogues of oestrone-3-O-sulphamate as potent steroid sulphatase inhibitors with reduced oestrogenicity. J Steroid Biochem Mol Biol 64: 269-275.

Qadan LR, Perez-Stable CM, Anderson C, D'Ippolito G, Herron A, Howard GA, Roos BA (2001) 2-Methoxyestradiol induces G2/M arrest and apoptosis in prostate cancer. Biochem Biophys Res Commun 285: 1259-1266.

Roth TM, Ramamurthy P, Ebisu F, Lisak RP, Bealmear BM, Barald KF (2007) A mouse embryonic stem cell model of Schwann cell differentiation for studies of the role of neurofibromatosis type 1 in Schwann cell development and tumor formation. Glia 55: 1123-1133.

Roth TM, Petty EM, Barald KF (2008a) The role of steroid hormones in the NF1 phenotype: focus on pregnancy. Am J Med Genet A 146A: 1624-1633.

Roth TM, Ramamurthy P, Muir D, Wallace M, Zhu Y, Chang L, Barald KF (2008b) Influence of hormones and hormone metabolites on the growth of Schwann cells derived from embryonic stem cells and on tumor cell lines expressing variable levels of neurofibromin. Dev Dyn 237: 513-524.

Shaw G, Morse S, Ararat M, Graham FL (2002) Preferential transformation of human neuronal cells by human adenoviruses and the origin of HEK 293 cells. FASEB J 16: 869-871.

Stengel C, Newman SP, Leese MP, Potter BVL, Reed MJ, Purohit A (2010) Class III beta-tubulin expression and in vitro resistance to microtubule targeting agents. Br J Cancer 102: 316-324.

Stengel C, Newman SP, Foster PA, Chander SK, Leese MP, Potter BVL, Reed MJ, Purohit A, Foster PA (2014) In vitro and in vivo properties of STX2484: a nonsteroidal anticancer compound active in taxane-resistant cells. Brit J Cancer 111: 300-308.

Tagg SL, Foster PA, Leese MP, Potter BVL, Reed MJ, Purohit A, Newman SP (2008) 2-Methoxyoestradiol-3,17-O,O-bis-sulphamate and 2-deoxy-Dglucose in combination: a potential treatment for breast and prostate cancer. Br J Cancer 99: 1842-1848.

Upadhyaya M (2011) Genetic basis of tumorigenesis in NF1malignant peripheral nerve sheath tumors. Front Biosci 16: 937-951.

Wallace MR, Marchuk DA, Andersen LB, Letcher R, Odeh HM, Saulino AM, Fountain JW, Brereton A, Nicholson J, Mitchell AL, Brownstein BH, Collins FS (1990) Type 1 neurofibromatosis gene: identification of a large transcript disrupted in three NF1 patients. Science 249: 181-186.

Xu GF, O'Connell P, Viskochil D, Cawthon R, Robertson M, Culver M, Dunn D, Stevens J, Gesteland R, White R, Weiss R (1990) The neurofibromatosis type 1 gene encodes a protein related to GAP. Cell 62: 599-608.

Zehou O, Fabre E, Zelek L, Sbidian E, Ortonne N, Banu E, Wolkenstein P, Valeyrie-Allanore L (2013) Chemotherapy for the treatment of malignant peripheral nerve sheath tumors in neurofibromatosis 1: a 10-year institutional review. Orphanet J Rare Dis 8: 127.

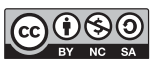

This work is licensed under the Creative Commons Attribution-Non-Commercial-Share Alike 4.0 International License. To view a copy of this license, visit http:// creativecommons.org/licenses/by-nc-sa/4.0/

Supplementary Information accompanies this paper on British Journal of Cancer website (http://www.nature.com/bjc) 